\title{
Recency judgments as a function of word frequency: A framing effect and frequency misattributions
}

\author{
ROBERT E. GUTTENTAG and DONNA CARROLL \\ University of North Carolina, Greensboro, North Carolina
}

\begin{abstract}
The effects of word frequency on judgments of recency of item presentation were examined in two experiments. Subjects in Experiment 1 were presented two mixed lists of high-and low-frequency words followed by a list assignment task for recognized items. It was found that subjects were biased toward assigning low-frequency words to the more recently presented list. Subjects in Experiment 2 were presented a single mixed list of high- and low-frequency words followed by either a relative recency of presentation judgment task or a relative primacy of presentation judgment task. Each word pair on the tests contained one high-frequency word and one low-frequency word. It was found that, for the recency judgment task, subjects were biased to select the low-frequency item as having been presented more recently. However, on the parallel primacy judgment task, there were no effects of word frequency; moreover, overall accuracy levels were higher with primacy than with recency instructions. We interpret the effects of word frequency on recency judgments in Experiments 1 and 2 in terms of a misattribution of frequency-related differences in recollection-based recognition. The finding that recency and primacy instructions produced different patterns of results provides further evidence (Flexser \& Bower, 1974) for an effect on performance of the way in which the temporal judgment task was framed.
\end{abstract}

Two general classes of theories have been proposed to explain how subjects make judgments of recency of occurrence of stimulus events. One set of theories proposes that the memory trace for presented items includes some form of temporal tag. Subjects may, for instance, judge recency of presentation on the basis of their recollection of the relationship between the presentation of a specific item and a temporal landmark, such as the beginning or end of a list (Anderson \& Bower, 1972; Flexser \& Bower, 1974; Hintzman \& Block, 1971; Hintzman, Block, \& Summers, 1973). A related view is that subjects may utilize their encoding of the serial order (DeLosh \& McDaniel, 1996; Whiteman, Nairne, \& Serra, 1994) of item presentation to make inferences about recency of item presentation.

An alternative view is that recency judgments are based, at least in part, on some measure of the memory strength of the to-be-judged items (Fozard \& Yntema, 1966; Hinrichs, 1970; Morton, 1968). According to this view, subjects implicitly assume that their memory for presented items will be stronger for more recently presented items than for less recently presented items. Strength theories thus propose that judgments of recency involve an inferential process in which variations in memory strength are attributed (or misattributed) to variations in delay since stimulus presentation.

The primary support for memory strength theories derives from studies that have examined recency judgments

This research was supported by a grant from the Research Council of the University of North Carolina at Greensboro. Correspondence should be addressed to R. E. Guttentag, Department of Psychology, University of North Carolina, Greensboro, NC 27412 (e-mail: guttenta@goodall uncg.edu). as a function of the number of times specific items were presented at study. This line of research has found that subjects tend to overestimate the recency of presentation of repeated items in comparison with once-presented items (Fozard \& Lapine, 1968; Fozard \& Yntema, 1966; Morton, 1968). According to memory strength theory, the increment in item memory strength that is produced by item repetition is misattributed by subjects to greater recency of presentation of the repeated items. There are, however, a number of findings that challenge strength misattribution interpretations of the item repetition effect-most notably, Hintzman and Block's (1971) finding that subjects maintain separate temporally tagged traces for repeated presentations of the same item.

A misattribution model of recency judgments would be greatly bolstered if it could be shown that a strengthrelated variable other than item repetition had a similar biasing effect on recency judgments. The primary purpose of the present study was to examine the effects of one such variable: word frequency. The low-frequency word advantage on tests of item recognition is well established (Glanzer \& Adams, 1990; Gregg, 1976). Accordingly, a strength misattribution model of recency judgments would predict that subjects should overestimate the recency of presentation of low-frequency words, relative to highfrequency words. Although the effects of word frequency on judgments of recency have not previously been examined, two studies assessing performance on a related "order reconstruction" task have failed to find a frequencyrelated biasing effect (DeLosh \& McDaniel, 1996; Whiteman et al., 1994). These studies, however, have examined performance solely with short (eight-item) lists of words; furthermore, the requirement that subjects order all items 
on a list may invoke a different set of strategies from those that are used on a more typical recency judgment task.

Two experiments utilizing somewhat different recency judgment paradigms were conducted in the present study. In the first experiment, subjects were presented two mixed lists of high- and low-frequency words. A recognition test followed list presentation, and, for each item marked as "old," subjects were instructed to judge whether the item had been presented on List 1 or List 2 . If subjects overestimate the recency of presentation of low-frequency words, they should exhibit a tendency to over assign low-frequency words to the second, more recently presented, list.

The task used in the second experiment required subjects to make judgments of relative recency (or relative primacy) of presentation for word pairs. Subjects were presented a single mixed list of high- and low-frequency words at study followed by the recency (or primacy) judgment task. Each word pair on the test contained one highfrequency word and one low-frequency word. We predicted that subjects would make more low-frequency selections than high-frequency selections when asked to select the more recent word from each pair, and, of course, we predicted the mirror-image pattern of results when subjects were instructed to select the word from each pair that had been presented earlier in the list.

\section{EXPERIMENT 1}

\section{Method}

Subjects. The subjects were 32 young adult college students whose participation fulfilled a course requirement.

Materials. All subjects were presented the same two lists at study Each list contained 32 target words ( 16 high-frequency words and 16 low-frequency words). The lists were generated from a set of $32 \mathrm{high}-$ frequency words (rank < 1,000, from Carroll, Davies, \& Richman, 1971) and 32 low-frequency words (rank $>10,000$, but $<25,000$ ). Half of the words of each frequency level were randomly assigned to List 1 and half to List 2. A random ordering of items on the study lists was generated within the restrictions that there were never more than 3 items of either word-frequency level presented in sequence and exactly 4 items of each word frequency were presented within each quartile of each list. An additional 4 nontarget moderate-frequency words were presented at the beginning and end of each list; these words did not appear on the recognition test.

The recognition test consisted of 96 items: the 64 target words from the two presentation lists plus 32 distractors ( 16 words of each frequency level). A random ordering of items on the recognition test was generated within the restrictions that each quartile of the recognition test list contained 4 target words of each frequency level from each study list and 4 distractors of each frequency level. Words on the recognition test were printed in two columns on one side of a sheet of paper. Next to each word were two dashed lines, one to be used for making recognition judgments and the other to be used (for the words judged as recognized) to indicate whether the word had been on the first or second study list.

Procedure. The words on each study list were auditorily presented at a rate of $2 \mathrm{sec}$ per item. The subjects were tested in two groups, with the order of presentation of the two lists counterbalanced across groups. The subjects were instructed to attend carefully to each word in preparation for a subsequent recognition memory test. A 5-min syllogistic reasoning filler task separated the presentation of the two lists. The recognition test immediately followed presentation of the second list of words. The subjects were instructed to put a check beside all the words that they thought had been presented on either of the study lists and, for all recognized items, to indicate on which list (first or second) they thought the item had been presented.

\section{Results and Discussion}

Table 1 presents the mean proportion of target and distractor words that were judged to be List 1 words, List 2 words, or new words, as a function of word frequency. An analysis of variance (ANOVA) revealed the typical wordfrequency effect pattern (Glanzer \& Adams, 1990); the overall hit rate (sum of first-and second-list responses) was higher for low-frequency words (.69) than for highfrequency words $(.56)\left[F(1,31)=28.44, M S_{\mathrm{e}}=5.08\right.$, $p<.01$, whereas the false-alarm rate was higher for highfrequency words than for low-frequency words $[F(1,31)=$ $\left.4.65, M S_{\mathrm{e}}=1.14, p<.05\right]$. The subjects were also more likely to indicate that false alarms had been presented on the first list than on the second $[F(1,31)=9.69, p<.01]$, suggesting that in the absence of recollection of any stimulus presentation context features, the subjects tended to make the reasonable judgment that the items had been presented on the less recent list. This finding is consistent with an increasing body of evidence indicating that subjects attribute false alarms to whichever factor in an experiment is associated with the lower level of recognition performance (Hoffman, 1997).

List assignment judgments were analyzed by first calculating, for each subject and for each type of item, the percentage of recognized items for which a correct list assignment judgment was made. On average, for highfrequency words, the subjects made correct list assignment judgments for $74 \%$ of the List 1 words and for $73 \%$ of the List 2 words; for low-frequency words, the subjects made correct list assignments for $60 \%$ of the List 1 words and for $80 \%$ of the List 2 words. An ANOVA revealed a significant main effect of presentation list $[F(1,31)=13.81$, $\left.M S_{\mathrm{e}}=2.58, p<.01\right]$, and a significant presentation list $\times$ word frequency interaction $\left[F(1,31)=9.14, M S_{\mathrm{e}}=3.55\right.$, $p<.01]$. Simple effects tests revealed that, for lowfrequency words, the subjects were significantly more accurate in their list assignment judgments for List 2 items than for List 1 items $\left[F(1,31)=30.13, M S_{\mathrm{e}}=2.02\right.$, $p<.01]$, but no effect of presentation list was found with high-frequency words $(F<1)$.

Thus, although there were no effects of word frequency on overall list assignment accuracy rates, an effect of word frequency was found on the pattern of list assignment judgments; for high-frequency words, the subjects were equally accurate in their judgments of List 1 versus List 2 items, whereas for low-frequency words, the subjects were

Table 1

Mean Proportions of List 1, List 2, and New Words

That Were Judged as List 1 (1), List 2 (2), and New (N)

as a Function of Word Frequency in Experiment 1

\begin{tabular}{ccccc}
\hline \multirow{2}{*}{$\begin{array}{c}\text { Presentation } \\
\text { Category }\end{array}$} & $\begin{array}{c}\text { Word } \\
\text { Frequency }\end{array}$ & \multicolumn{3}{c}{ Recognition-Test Response } \\
\cline { 3 - 5 } & high & .41 & .15 & $\mathrm{~N}$ \\
\hline List 1 & low & .42 & .28 & .34 \\
& high & .15 & .41 & .44 \\
List 2 & low & .13 & .55 & .32 \\
& high & .10 & .05 & .85 \\
New & low & .06 & .04 & .90 \\
\hline
\end{tabular}


more accurate for List 2 items than for List 1 items, reflecting a general bias toward judging that low-frequency target words had been presented on the more recent list.

\section{EXPERIMENT 2}

Experiment 2 examined the effects of word frequency on judgments of recency using a relative recency of presentation judgment task and a relative primacy of presentation judgment task. ("Select the item that occurred earlier in the list.") Logically, of course, there should be no overall accuracy level differences between recency judgment and primacy judgment performance, and any variables that affect recency judgments should have a matching, albeit mirror-image, influence on primacy judgments. Surprisingly, however, there is some evidence that primacy and recency judgments may not be simply the psychological inverse of each other; Flexser and Bower (1974) found that subjects were more accurate when given recency judgment instructions than when given "distance" judgment instructions. ("Which item was presented more distantly back in time on the presentation list?")

\section{Method}

Subjects. The subjects were 62 students whose participation fulfilled a course requirement.

Materials. The study list consisted of 24 high-frequency words and 24 low-frequency words, along with 4 medium-frequency filler words presented at the beginning and end of the list. The 48 target words were ordered on the presentation list in such a manner that it was possible to construct a temporal order judgment test with a presentation-list lag of exactly 24 items between members of each test pair.

The temporal order test consisted of 24 word pairs printed in a predetermined random order on a single sheet of paper. Each pair contained one high-frequency word and one low-frequency word from the study list. The high-frequency word had been presented more recently on the study list for half of the pairs; the more recent item was also counterbalanced across left-right position on the printed page.

Procedure. The subjects were tested in two group sessions. The only difference in procedure between the sessions was that the reverse order of presentation of items on the study list was used in the two sessions; this procedure served to counterbalance the correct response for each test pair across the two groups.

Prior to study list presentation, the subjects were informed that they would be presented a list of words, which would be followed by a memory test. No mention was made of recency or primacy judgments. The presentation list was then read aloud at a rate of $2 \mathrm{sec}$ per item. The surprise recency/primacy judgment test was administered immediately following study list presentation. Written instructions were provided, and a randomly selected half of the subjects in each group received recency judgment instructions and half received primacy instructions. The instructions described the nature of the judgment that the subjects were to make and included examples to ensure that the subjects understood the task. The subjects were instructed to circle the word from each pair that they thought had occurred either earlier on the list than the other word (primacy instructions) or more recently than the other word (recency instructions).

\section{Results and Discussion}

Table 2 presents the mean proportions of correct judgments as a function of instructions (primacy vs. recency) and the word frequency of the correct item. An ANOVA revealed significant main effects of instructions $[F(1,60)=$ $\left.10.25, M S_{\mathrm{e}}=5.82, p<.01\right]$ and word frequency $[F(1,60)=$ $\left.14.22, M S_{\mathrm{e}}=3.25, p<.01\right]$ and a significant instruc-
Table 2

Mean Proportion of Correct Judgments as a Function of the Word Frequency of the Correct Item With Primacy and Recency Instructions

\begin{tabular}{ccc}
\hline & \multicolumn{2}{c}{ Word Frequency } \\
\cline { 2 - 3 } Instructions & High & Low \\
\hline Primacy & .74 & .69 \\
Recency & .52 & .68 \\
\hline
\end{tabular}

tions $\times$ word frequency interaction $[F(1,60)=15.87, p<$ .011 . Simple effects tests revealed that when the high-frequency word was the correct item, the subjects were significantly more accurate when the task was performed under primacy instructions than under recency instructions $\left[F(1,60)=20.56, M S_{\mathrm{e}}=5.40, p<.01\right]$; no effect of instructions was found when the low-frequency word was the correct item. In addition, with recency judgment instructions, the subjects were correct significantly more often when the low-frequency word was correct than when the high-frequency word was correct $[F(1,60)=16.01$, $\left.M S_{\mathrm{e}}=3.25, p<.01\right]$; no effect of word frequency was found under primacy judgment instructions.

These findings are consistent with the predicted biasing effect of word frequency on temporal judgments; overall, the subjects overestimated the relative recency of presentation of low-frequency words, relative to highfrequency words. The effect, however, was limited to recency judgments; when the subjects were instructed to select the word that occurred earlier in the list, there were no significant effects of word frequency on performance. In addition, despite the fact that the two sets of instructions were logically identical (indeed, a minor transformation converts one set of instructions into the other), the subjects had a higher overall accuracy rate with primacy instructions than with recency instructions.

\section{GENERAL DISCUSSION}

The subjects in both experiments overestimated the recency of presentation of low-frequency study list items, relative to high-frequency study list items. One possible way to explain these findings is to posit frequency-related differences in the rate of forgetting of source-list information. More specifically, we might hypothesize that source-list information may degrade more rapidly for low-frequency words than for highfrequency words. If this were the case, then one would expect relatively more List 2 assignments than List 1 assignments for low-frequency words, relative to high-frequency words. One problem for this approach, however, is that it is not clear why the degrading of list-source information should occur more rapidly for low-frequency words. On the contrary, findings from word recognition studies suggest a low-frequency advantage for the retention of a broad variety of features of the context of item encoding (Bornstein \& LeCompte, 1995; Guttentag \& Carroll, 1994). Alternatively, the present findings may reflect frequency-related differences in some form of memory strength. According to this view, when the subjects in the present study were required to make recency judgments, they misattributed word-frequency-related differences in memory strength to a frequency-related difference in recency of item presentation.

It should be emphasized that the term memory strength as used here is meant broadly to refer to whatever factor or factors are responsible for word-frequency differences in judgments of recognition. A number of prominent models of recognition have proposed that there are two potentially independent bases for recognition memory judgments (Gar- 
diner, 1988; Jacoby, 1991; Mandler, 1980): recollection and familiarity. Recollection-based recognition depends on the retrieval of contextual details from the original episode of item-presentation at study. Familiaritybased recognition, in contrast, is distinguished by a subjective sense of having experienced a stimulus recently, in the absence of recollection of episodic information from the prior presentation.

The present findings by themselves do not specify the locus of the effect of word frequency on recency judgments. However, the strengthmisattribution approach presumes that the same factor responsible for the effect of word frequency on judgments of recognition is responsible for the recency judgment effects found here. Studies of the recognitionmemory word-frequency effect strongly suggest that the low-frequency recognition advantage is largely a recollection-based phenomenon (Gardiner \& Java, 1990; Guttentag \& Carroll, 1994). Thus, the most parsimonious explanation for the present findings is that the recencyjudgment word-frequency effect is also largely a recollection-based phenomenon.

One potential problem for a recollection-misattribution explanation for the present findings is that it presumes that recollection, like familiarity, is a continuous rather than discrete phenomenon. Recollection has typically been characterized as an all-or-none phenomenon (Jacoby, 1991). This, however, may not necessarily be the case. For example, subjects may retrieve more encoding context features for some items than for others; in this case, judgments of recency may vary as a function of the number of encoding context features retrieved. Indeed, it would seem necessary to posit some form of continuous recollection function to explain why confidence judgments may vary across recollected items on tests of recognition (Gardiner \& Java, 1993).

A focus on the misattribution of frequency-related differences in recollection-based recognition as the source of the recency judgment bias found here also raises the potential problem that studies of free recall have generally found a high-frequency word advantage (when frequency is manipulated between lists) or else no consistent effects of word frequency at all (when frequency is manipulated within lists) (see Gregg, 1976). Accordingly, the present view would entail the further assumption that there is a component of free recall that favors high-frequency words but that does not influence performance on recognition or recency judgment tasks; at present, such a component has yet to be identified.

The most surprising findings from the present study involved the effects of instructions on performance in Experiment 2. The frequency effects found under recency instructions were not found with primacy instructions. Moreover, overall levels of accuracy were higher under primacy instructions than under recency instructions. As was noted by Flexser and Bower (1974), any difference between the effects of these two forms of instructions is quite puzzling because the only difference between a primacy judgment and a recency judgment would seem to be that the opposite answer is required on any particular trial. Notably, whereas Flexser and Bower found superior performance with recency than with "distance" instructions, we found that performance was better with primacy instructions than with recency instructions. Apparently, not only are primacy instructions not the psychological inverse of recency instructions but primacy instructions are also not psychologically identical to distance instructions.

These findings are reminiscent of studies of problem solving that have found that subtle differences in the way in which problems are presented can have a large effect on the strategies that subjects use to perform the task (Kahneman \& Tversky, 1984; Wason \& Johnson-Laird, 1972; Woodworth \& Sells, 1935), a phenomenon that has been termed the framing effect. The possibility that framing effects might occur on remembering tasks has received relatively little attention. Recently, however, Roediger and McDermott (1995) found evidence for a framing effect on recognition memory performance. Roediger and McDermott tested recognition memory using a two-alternative forced-choice procedure, and subjects were instructed either to select the old item from each test pair or to select the new item from each test pair. Roediger and McDermott found that subjects performed with a higher level of accuracy when they were instructed to select distractors rather than targets; apparently, the two different ways in which the task was framed elicited somewhat different, and differentially effective, recognition judgment strategies.
Experiment 2 of the present study provides further evidence for a framing effect on a remembering task. The subjects in both groups were provided identical instructions at study. Nonetheless, the provision of different, but logically isomorphic, instructions at test produced different levels and patterns of performance. This finding suggests that, under primacy instructions, the subjects in Experiment 2 used strategies different from, or based their judgments on sources of information different from, those used under recency instructions. It is possible, for instance, that the subjects may have based their judgments somewhat more on familiarity than recollection under primacy instructions, relative to under recency instructions. This hypothesis is consistent with the absence of word-frequency effects that were found under primacy instructions. Further research is required to determine whether this difference, or some other, is responsible for the framing effect found here.

\section{REFERENCES}

ANDERSON, J. R., \& Bower, G. H. (1972). Recognition and retrieval processes in free recall. Psychological Review, 79, 97-123.

Bornstein, B. H., \& LeCoMPTE, D. (1995, November). Stimulus characteristic effects on source monitoring. Paper presented at the annual meeting of the Psychonomic Society, Los Angeles.

Carroll, J. B., Davies, P., \& Richman, B. (1971). Word frequency book. New York: Houghton Mifflin.

DeLosh, E. L., \& McDaniel, M. A. (1996). The role of order information in free recall: Application to the word-frequency effect. Journal of Experimental Psychology: Learning, Memory, \& Cognition, 22, $1136-1146$.

FLEXSER, A. J., \& BowER, G. H. (1974). How frequency affects recency judgments: A model for recency discriminations. Journal of Experimental Psychology, 103, 706-716.

FozARD, J. L., \& LAPINE, R. (1968). Comparison of the apparent recency of pictures and names of common objects [Abstract]. American Psychologist, 23, 638.

FozARD, J. L., \& YNTEMA, D. B. (1966). The effect of repetition on the apparent recency of pictures [Abstract]. American Psychologist, 21, 879.

GARDINER, J. M. (1988). Functional aspects of recollective experience. Memory \& Cognition, 16, 309-313.

GaRDINER, J. M., \& JAVA, R. I. (1990). Recollective experience in word and nonword recognition. Memory \& Cognition, 18, 23-30.

GARDINER, J. M., \& JAVA, R. I. (1993). Recognizing and remembering. In A. Collins, M. A. Conway, S. E. Gathercole, \& P. E. Morris (Eds.), Theories of memory (pp. 163-188). Hillsdale, NJ: Erlbaum.

Glanzer, M., \& Adams, J. K. (1990). The mirror effect in recognition memory: Data and theory. Journal of Experimental Psychology: Learning, Memory, \& Cognition, 16, 5-16.

GREGG, V. (1976). Word frequency, recognition, and recall. In J. Brown (Ed.), Recall and recognition (pp. 183-216). New York: Wiley.

GutTentaG, R, E., \& CARROLL, D. (1994). Identifying the basis for the word frequency effect in recognition memory. Memory, 2, 255-273.

HinRICHS, J. V. (1970). A two-process memory strength theory of judgment of recency. Psychological Review, 77, 223-233.

HintZMAN, D. L., \& B LOCK, R. A. (1971). Repetition and memory: Evidence for a multiple trace hypothesis. Journal of Experimental Psychology, 88, 297-306.

Hintzman, D. L., Block, R. A., \& Summers, J. J. (1973). Contextual associations and memory for serial position. Journal of Experimental Psychology, 97, 220-229.

HofFMAN, H. G. (1997). The role of memory strength in reality monitoring decisions: Evidence from source attribution biases. Journal of Experimental Psychology: Learning, Memory, \& Cognition, 23, 371-383.

JACOBY, L. L. (1991). A process dissociation framework: Separating automatic from intentional uses of memory. Journal of Memory \& Language, 30, 513-541.

Kahneman, D., \& Tversky, A. (1984). Choices, values, and frames. American Psychologist, 39, 341-350.

MANDLER, G. (1980). Recognizing: The judgment of previous occurrence. Psychological Review, 87, 252-271.

MORTON, J. (1968). Repeated items and decay in memory. Psychonomic Science, 10, 219-220. 
Roediger, H. L., III, \& McDermott, K. B. (1995, November). A framing effect in recognition memory. Paper presented at the annual meeting of the Psychonomic Society, Los Angeles.

WASON, P. C., \& Johnson-LaIRd, P. N. (1972). Psychology of reasoning. Cambridge, MA: Harvard University Press.

Whiteman, H. L., Nairne, J. S., \& Serra, M. (1994). Recognition and recall-like processes in the long-term reconstruction of order. $\mathrm{Mem}$ ory, 2, 275-294
Woodworth, R. S., \& Sells, S. B. (1935). An atmosphere effect in formal syllogistic reasoning. Journal of Experimental Psychology, 18, $451-460$.

(Manuscript received April 12, 1996; revision accepted for publication March 19, 1997.) 